\title{
Kreatif Hashtag (Analisis Deskriptif Makna Penggunaan Hashtag Pada Iklan Tokopedia \#MulaiAjaDulu Di Youtube)
}

\author{
Christian, Gregorius Genep Sukendro \\ Christian.915150028@stu.untar.ac.id,Geneps@fikom.untar.ac.id \\ Fakultas Ilmu Komunikasi Universitas Tarumanagara
}

\begin{abstract}
This study are discover the meaning of the use of hashtag in Tokopedia ads \#MulaiAjaDulu on youtube. This study uses descriptive qualitative research methods. Data collection is done by using interview techniques, literature study, online data research. The research data uses data reduction, data presentation, and drawing conclusions and verification. Communication is the process of conveying information, ideas, and messages verbally and nonverbally from one person to another. Mass Communication is a form of communication that utilizes both print, electronic, and cyber (online) media channels. Communication is also done on the promotion of a product using advertising. Advertising that continues to grow with increasingly interesting creative ideas, one of which is the use of hashtag on Tokopedia Ads. The results of this study the use of Hashtag has a meaning that is the use of Hashtag in an advertisement according to the author because the hashtag that moves on social media and hashtag can also be made by anyone who becomes a hot topic to discuss, therefore with the hashtag prefixed this ad makes the ad easier to reach by the target. The use of Hashtag also makes it easy for sellers to find out how much advertising is seen, and marketing using Hashtag can be more developed than the usual marketing.
\end{abstract}

Keywords: Mass Communication, Creativity, Hashtag, Style and type of words, mean

\begin{abstract}
Abstrak
Penelitian ini adalah menemukan makna penggunaan hashtag yang ada pada iklan Tokopedia \#MulaiAjaDulu di youtube. Penelitian ini menggunakan metode penelitian kualitatif deskriptif. Pengumpulan data dilakukan dengan menggunakan teknik wawancara, studi kepustakaan, penulusuran data online. Data penelitian yang digunakan menggunakan reduksi data, penyajian data, dan penarikan kesimpulan dan verifikasi. Komunikasi merupakan proses penyampaian informasi, gagasan, dan pesan secara verbal maupun nonverbal dari seseorang ke orang lain. Komunikasi Massa adalah bentuk komunikasi yang memanfaatkan saluran media baik cetak, elektronik, maupun media cyber (online). Komunikasi pun dilakukan terhadap promosi suatu produk menggunakan iklan. Iklan yang terus berkembang dengan ideide kreatif yang semakin menarik salah satunya penggunaan hashtag di Iklan Tokopedia. Hasil dari penelitian ini penggunaan hashtag memiliki makna yang di dapat yaitu penggunaan hashtag dalam sebuah iklan menurut penulis karena hashtag yang bergeraknya di sosial media dan hashtag juga bisa dibuat oleh siapapun yang menjadi sebuah topik yang hangat untuk diperbincangkan maka dari itu dengan adanya tagar di awalan sebuah iklan tersebut hal ini membuat iklan itu lebih mudah untuk dijangkau oleh targetnya. Penggunaan hashtag juga memberikan kemudahan untuk penjual mencari tahu seberapa banyak iklan itu di lihat, dan pemasaran menggunakan hashtag bisa lebih berkembang dari pemasaran yang biasa dilakukan.
\end{abstract}

Kata kunci: Komunikasi Massa, Kreativitas, Hashtag, Gaya dan jenis kata, Makna 


\section{Pendahuluan}

Komunikasi merupakan proses penyampaian pesan, gagasan, dan informasi secara verbal dan nonverbal dari seseorang. Komunikasi disebut juga suatu proses pertukaran informasi antara individu melalui sistem lambang-lambang, tanda atau tingkah laku. Youtube yang muncul sebagai media baru yang di dukung dengan adanya kemampuan internet yang memiliki salah satu fungsi komunikasi sebagai komunikasi massa. Youtube yang muncul sebagai media baru yang di dukung dengan adanya kemampuan internet yang memiliki salah satu fungsi komunikasi sebagai komunikasi massa. Komunikasi massa ditujukan kepada masyarakat luas, tidak hanya kepada seseorangan. Pesan dari komunikasi massa yaitu dapat berupa peristiwa, fakta atau opini

Pertumbuhan Iklan saat ini mengalami perubahan yang cukup pesat. Periklanan (advertising) menurut Kustadi Suhendang merupakan suatu proses komunikasi massa yang melibatkan sponsor tertentu, yakni pemasangan iklan (pengiklan) yang membayar jasa sebuah media massa atas penyiaran iklannya, misalnya melalui program siaran televisi. Iklan dapat dilihat melalui berbagai macam media, misalnya majalah, surat kabar, radio, Tv, papan reklame, dan sebagainya. Digenerasi sekarang, perhatian masyarakat semakin berkurang, hal ini yang menjadi tantangan bagi pengiklan untuk membuat iklan yang berhasil menyita dan menarik perhatian masyarakat secara singkat. Untuk membuat sebuah iklan yang baik dan menarik dalam era modern saat ini, seorang pembuat iklan harus menghadirkan suatu karya iklan yang baru, unik, out of box.

Kemampuan seseorang untuk menciptakan sesuatu yang baru, baik berupa gagasan maupun karya nyata, dalam bentuk ciri-ciri apititude maupun non apititude, dalam karya baru maupun kombinasi dengan hal-hal yang sudah ada, dan semuanya relatif berbeda dengan yang sudah ada sebelumnya dan itu disebut kreativitas.

Hashtag merupakan kata kunci kecil yang ditandai dengan tanda pagar (\#) yang saat ini sangat popular. Hampir di semua situs media sosial menggunakan hashtag. Penggunaan hashtag atau tanda pagar (\#) memiliki makna dari kata-kata yang terdapat dalam hashtag tersebut. Menurut Mulyana (2017: 281) makna muncul dari hubungan khusus antara kata (sebagai simbol verbal) dan manusia. Makna tidak melekat pada kata-kata, namun kata-kata membangkitkan makna dalam pikiran orang. Jadi, tidak ada hubungan langsung antara suatu objek dan simbol yang digunakan untuk merepresentasikannya..

Hashtag muncul pertama kali Saat ini banyak digunakan dalam kehidupan sehari-hari, termasuk percakapan di luar twitter. Pesatnya pertumbuhan penggunaan hashtag ini menunjukan bahwa hashtag ini memiliki banyak sekali manfaat dari sekedar memusatkan maupun mendorong sebuah percakapan, dan hashtag yang saat ini bisa digunakan sebagai media promosi atau beriklan dengan penggunaan makna kata yang unik. Hashtag digunakan untuk menggolongkan tema atau topik yang lebih spesifik dalam media sosial, dan sisi lain dari hashtag juga mempermudah orang lain untuk mencari topik yang saling berhubungan. Saat ini penggunaan hashtag dengan slogan yang unik menjadi andalan dalam strategi pemasaran banyak digunakan karena memudahkan sesorang dalam melalukan pencarian dan menarik perhatian masyarakat.

Tokopedia yang merupakan salah satu e-commerce terbesar di Indonesia. Dengan kampanye iklannya \#MulaiAjaDulu yang dihadirkan dalam serial video 
berdurasi pendek dengan bermacam versi yang dapat di temukan di TV, youtube ,dll. Iklan ini bertujuan memberikan pengalaman baru untuk masyarakat mewujudkan mimpinya menjadi kenyataan, bila kamu mencoba memulainya. Kampanye iklan ini tidak hanya ada di dalam video pendek tetapi juga di buat di berbagai media cetak, digital, dan media sosial populer di Indonesia. Penulis tertarik melakukan penelitian terhadap makna penggunaan hashtag iklan \#MulaiAjaDulu di youtube. Karena youtube memiliki pengguna yang sangat banyak di banding media sosial lainnya.

Penelitian ini dilakukan untuk mengatahui bagaimana makna penggunaan hashtag dalam iklan Tokopedia \#MulaiAjaDulu di youtube.

\section{Metode Penelitian}

Metode penelitian yang digunakan penulis adalah metode penelitian kualitatif. Menurut Muri Yusuf (2014) dalam buku Metode Penelitian Kuantitatif, Kualitatif, dan Penelitian Gabungan, menjelaskan penelitian kualitatif merupakan suatu strategi inquiry yang menenkankan pencarian makna, pengertian, konsep, karakteristik, gejala, simbol, maupun, deskripsi tentang suatu fenomena, fokus, dan mutimetode.

Jenis penelitian yang digunakan adalah deskriptif. Metode Penelitian deskriptif menurut Nazir (2011) merupakan suatu metode dalam meneliti status sekelompok manusia, suatu objek, suatu set kondisi, suatu sistem pemikiran, ataupun suatu kelas peristiwa pada masa sekarang.

Strategi penelitian yang penulis gunakan dalam penelitian ini menggunakan metode fenomenologi. Penelitian fenomenologi menurut Husserl dalam Moleong (2008) fenomenologi adalah pandangan cara berfikir yang menekankan pada fokus kepada pengalaman-pengalaman subjektif manusia dan interpretasi-interpretasi dunia. Dalam hal ini, fenomenologis ingin memahami bagaimana dunia muncul kepada orang lain

Penelitian yang dilakukan penulis terdapat metode pengumpulan data yang bertujuan agar penelitian ini dapat mengumpulkan data dan informasi yang akurat, yaitu: wawancara, studi kepustakaan, Penelusuran data online.

Teknik analisis data dalam penelitian kualitatif , data penelitian diperoleh dari berbagai sumber dan dengan teknik pengumpulan data yang di dapat bermacammacam (triangulasi) dilakukan secara terus-menerus sampai datanya jenuh. Menurut Miles dan Huberman dalam (Sugiyono, 2016) mengemukakan bahwa aktivitas dalam analisis data ada tiga, yaitu: reduksi data, penyajian data, penarikan kesimpulan dan verifikasi.

\section{Hasil Temuan dan Diskusi}

Berdasarkan dari hasil penelitian yang dilakukan penulis akan menjelaskan hasil temuan yang sudah di dapat saat penelitian berlangsung. Hasil temuan ini di dapat melalui hasil wawancara dengan para narasumber, berikut di bawah ini:

a. Youtube sebagai media baru

Berdasarkan hasil wawancara dengan Arsyad selaku creative head group Flock Company Berdasarkan hasil wawancara yang penulis temukan dari media baru yang memiliki pengertian bahwa media baru adalah berbagai alat perangkat komunikasi yang memiliki beberapa jenis yang sama, yang mana selain baru dimungkinkan dengan digitalisasi dan ketersediannya yang luas untuk pengguna pribadi sebagai alat komunikasi Dari teori yang penulis pilih komunikasi yang diinginkan sesuai karena 
komunikasi iklan lewat tv orang-orang bisa langsung mencari informasi melewati sosial media karena lebih cepat dan mudah begitu sebaliknya jika iklan di lakukan youtube yang salah satu media sosial ini bertujuan agar saat orang tersebut telah melihat iklan tersebut, dan setelah melakukan pencarian akhirnya informasi itu akan berkembang.

b. Gaya dan jenis kata dalam iklan hashtag

Dalam pembuatan iklan menggunakan hashtag pemilihan gaya dan jenis kata pun menjadi bagian yang penting untuk digunakan agar kata yang digunakan dapat menyimpulkan pesan iklan itu sendiri. Terdapat Alternatif gaya penyampaian pesan dan jenis kata pun memiliki beberapa jenis, yaitu:

1. Ekslporatif:

Mengeksplorasi/mengulas dengan tajam hakikat produk dan jasa dengan katakata yang akurat. Kata-kata yang akan digunakan tidak boleh bermakna ganda, harus bermakna tunggal. Kata-kata yang dipakai bertendensi menguras habis daya kemampuan yang terdapat di fisik maupun psikis produk atau jasa yang di iklankan. Ekplorisasi kata-kata yang dimaksud bertendensi itu menguatkan dan menunjukkan fakta yang sebenarnya. Flock menerapkan hal tersebut dalam pemilihan gaya dan jenis kata dalam \#MulaiAjaDulu yang jenis katanya dipilih karena bahasa yang digunakan tidak terlalu baku atau tidak terlalu kekinian.

2. Naratif:

Gaya bahasa dibikin semenarik mungkin dan pilihan katanya mengandung sebuah unsur imajinasi dan membuai dengan tetap mengedepankan kebenaran dan fakta. Dalam hashtag \#MulaiAjaDulu yang bukan merupakan sebuah narasi hanya terdapat 3 kata ini tetap memiliki gaya bahasa yang mengandung unsur imajinasi saat orang-orang melihatnya. Dalam iklan ini memberikan gerakan keberanian dan kebenaran yang sesuai.

3. Argumentasi:

Iklan Tokopedia ini memberikan argumentasi yang cukup mempengaruhi audience dengan makna yang terkandung dalam \#MulaiAjaDulu. Argumen yang mempengaruhi audience dengan kalimat yang digunakan adalah sebuah gerakan untuk mengajak orang-orang melakukan apa yang dia inginkan tanpa keraguan. Dalam kalimat tersebut pun bisa menyerang kompetitor lainnya dan cukup mempengaruhi audience,

4. Retoris

Retoris yang ada dalam \#MulaiAjaDulu dibuat dengan kebenaran dari riset yang sudah dilakukan dan dari iklan ini tidak mengharapkan jawaban atau komentar, tetapi iklan lebih dibuat untuk menyadarkan audience, gaya dan jenis kata yang dibuat cukup sederhana tetapi mampu di mengerti orang banyak saat membaca,

c. Proses kreatif dalam \#MulaiAjaDulu

Tokopedia mengiinginkan sebuah kampanye iklan dengan komunikasi yang berbeda yang sebelumnya 'sudah cek Tokopedia belum?' dan 'ciptakan peluangmu. Dari 2 materi komunikasi iklan itu agar orang-orang sudah bisa melakukan semuanya di Tokopedia, semua yang dibutuhkan konsumen ada di Tokopedia. Maka dari itu Flock sebagai agensi membuat kampanye iklan dari lanjutan iklan sebelumnya yaitu \#MulaiAjaDulu. \#MulaiAjaDulu dipilih karena lebih relevan, dan lebih mudah di mengerti satu Indonesia khususnya kata-kata digunakan dalam percakapan sehari-hari. Selanjutnya dalam proses kreatif pembuatan iklan yang menggunakan hashtag harus singkat padat dan jelas untuk memudahkan orang-orangya lebih mudah diingat, 
menarik, memiliki keunikan tersendiri. Seperti campaign-campaign dari promosi produk atau event yang mengajak pengguna sosial media melakukan syarat dan ketentuan untuk mengikuti program tersebut dengan salah satunya adalah mencantumkan sebuah hashtag yang ditetapkan pembuat acara. Dengan kesalahan dalam mengetik hashtag karena penggunaan katanya yang rentan salah makan calon peserta tersebut akan gagal mengikuti program acara tersebut. Maka dari itu pemilihan kata yang ditentukan termasuk dalam bagian dari proses kreatif dalam pembuatan hashtag yang sangat diperhatikan.

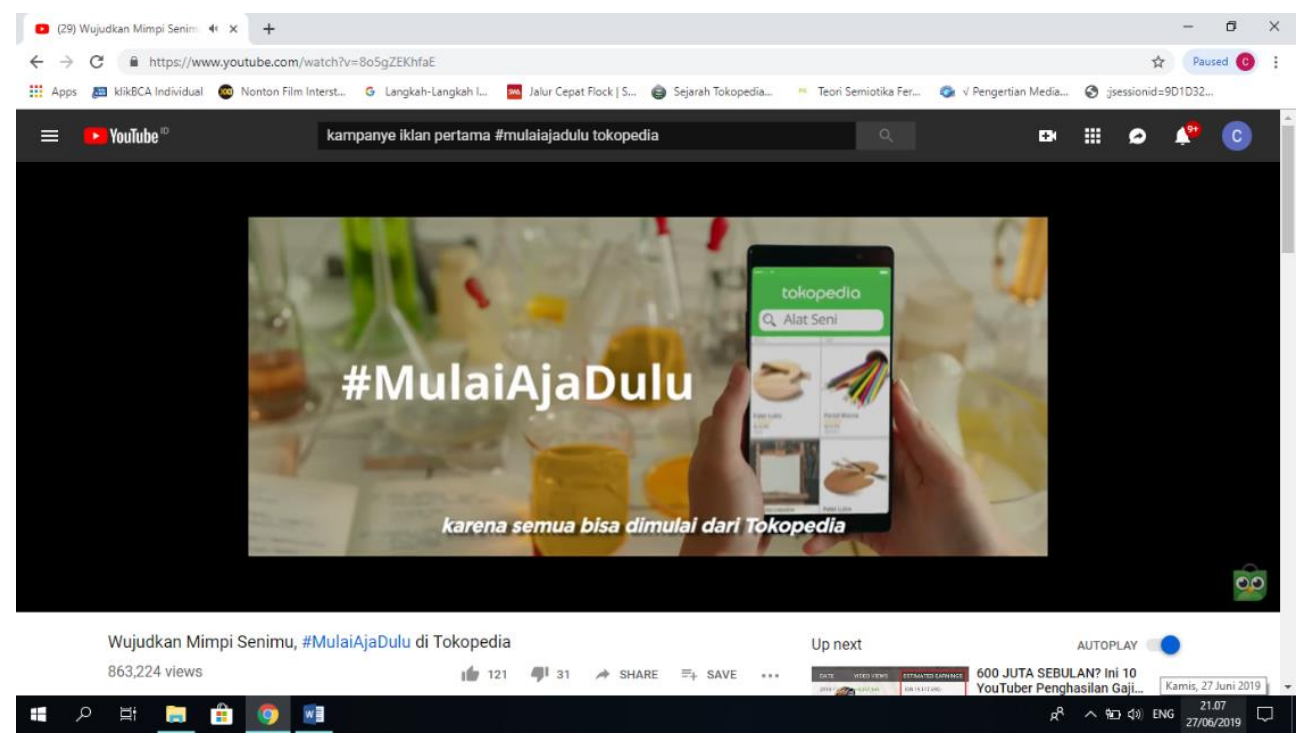

Gambar 1. Salah satu iklan hashtag Tokopedia 'wujudkan mimpi senimu \#MulaiAjadulu di Tokopedia

d. Makna dalam penggunaan iklan hastag \#

Penggunaan hashtag bisa dikatakan sebagai ikon dari produk misalkan \#MulaiAjaDulu itu punya Tokopedia dan dalam makna hashtag ini memiliki maksud tersendiri bagi penggunanya karena memang yang membicarakan hal ini biasanya itu orang bukan brand, penggunaan hashtag itu digunakan oleh orang bukan brand. Sehingga penggunaan hashtag itu sendiri biasanya lebih di kaitkan denggan pengguna media sosial seperti twitter dan Instagram . memang dari keinginan manusia itu sendiri ingin perubahan. Dan makna dari penggunaan hashtag bagi penjualnya bertujuan untuk mencari tahu seberapa banyak orang yang mencari iklan tersebut, apakah audience dari target terpenuhi, bahkan media pemasaran yang telah di gunakan akan berkembang lebih jauh dari pemasaran yang sudah di tentukan karena hashtag memiliki jangkauannya sangat luas. Berdasarkan fungsi hashtag yang perannya sangat efektif di sosial media saat ini, maka Flock sebagai agensi menggunakan fitur hashtag ini di iklan Tokopedia. Dari kata-kata yang dipilih MulaiAjaDulu dari kata 'mulai' ini cukup menonjol dalam iklan tersebut. Kata 'mulai' yang diartikan sebagai kata untuk mengawali suatu tindakan, sebagai awalan melakukan sesuatu, atau bisa disebut sebagai kata penggerak. 


\section{Simpulan}

Setelah penulis melakukan penelitian mengenai makna kreatif penggunaan hashtag dalam iklan Tokopedia versi \#MulaiAjaDulu di Youtube. Dari hasil penelitian yang penulis temukan penggunaan hashtag memang sudah ada saat munculnya Twitter dan Instragram. Dengan menggunakan hashtag informasi yang ditambahkan akan otomatis tergabung menjadi sebuah sekelompok artikel dengan hashtag yang sama di dalam satu halaman. hashtag juga mempermudah orang lain untuk mencari topik yang saling berhubungan untuk menandainya sebagai kata kunci. Flock membuat iklan menggunakan hashtag karena fungsi dari penggunaan hashtag tersebut sangat banyak dan mempengaruhi konsumen.

Untuk membuat hashtag perlu pemilihan kata yang harus di cermati dan jelas agar pembaca atau orang yang melihat iklan itu langsung cepat ditangkap konsumen ditambah dengan kata-kata yang digunakan itu mudah diingat, tidak terlalu panjang dan bahasa yang digunakan adalah bahasa yang digunakan orang sehari-hari.

Setelah itu makna kreatif yang di dapat dari penggunaan hashtag dalam sebuah iklan karena hashtag yang bergeraknya di sosial media dan hashtag juga bisa dibuat oleh siapapun yang menjadi sebuah topik yang hangat untuk diperbincangkan maka dari itu dengan adanya tagar di awalan sebuah iklan tersebut hal ini membuat iklan itu lebih mudah untuk dijangkau oleh targetnya. Penggunaan hashtag juga memberikan kemudahan untuk penjual mencari tahu seberapa banyak iklan itu di lihat, dan pemasaran menggunakan hashtag bisa lebih berkembang dari pemasaran yang biasa dilakukan. Maka dari itu penggunaan hashtag di iklan youtube merupakan salah satu teknik iklan yang berhasil untuk menaikkan traffic iklan ini.

\section{Ucapan Terima Kasih}

Ucapan terima kasih penulis berikan kepada narasumber yang telah meluangkan waktunya dan memberikan informasi kepada peneliti selama proses pengumpulan data dalam penelitian ini. Peneliti juga ingin mengucapkan terima kasih kepada Dosen Pembimbing serta Fakultas Ilmu Komunikasi Universitas Tarumanagara.

\section{Daftar Pustaka}

Gambaran Umum Flock Company. (n.d.). Juni 12, 2018.

http://repository.umy.ac.id/bitstream/handle/123456789/21485/BAB\%20II.pdf?sequ ence $=2 \&$ isAllowed $=\mathrm{y}$

McQuail, Dennis. (2011). Teori Komunikasi Massa. Jakarta: Salemba Humanika Mulyana, Deddy (2017). Ilmu Komunikasi Suatu Pengantar. Bandung: PT. Remaja Rosdakarya.

Nazir, Mohammad, Ph.D. (2011) Metode Penelitian. Jakarta: Ghalia Indonesia Sejarah Hashtag. (2013). Juni 12, 2018. https://marketing.co.id/sejarah-hashtag/ Sugiyono. (2016). Memahami Penelitian Kualitatif. Bandung: Alfabeta.

Sugiyono. (2016). Manajemen, Kiat, dan Strategi Periklanan. Bandung: Nuansa Yusuf, Muri. (2014). Metode Penelitian Kuantitarif, Kualitatif, \& Penelitian Gabungan. Jakarta: PT. Fajar Interpratama Mandiri. 